\title{
PENGARUH FASILITATOR PENDAMPING TERHADAP TINGKAT KINERJA KEUANGAN UNIT PENGELOLA KEUANGAN PINJAMAN BERGULIR PROGRAM NASIONAL PEMBERDAYAAN MASYARAKAT MANDIRI PERKOTAAN
}

\section{(The Effect of Faciltator Accompanying on Financial Level Performance of Revolving Loan Financial Manager of National Program on Urban Independent Community Empowerment)}

\author{
Tona Aurora Lubis ${ }^{1}$,Firmansyah ${ }^{2}$ dan Saiful ${ }^{3}$ \\ ${ }^{1}$ Dosen pada Program MM, Ketua Prodi Manajemen, FEB Unja. \\ ${ }^{2}$ Dosen pada Program FEB Unja, Jurusan Manajemen \\ ,${ }^{3}$ Tenaga Ahli Manajemen keuangan dan Micro Finance PNPM Mandiri Perkotaan- \\ Palembang,
}

\begin{abstract}
National Program on Independent Urban City Citizehsip (PNPM MP) has specific schema on helping Micro Business by capital provision with revolving principle and human resource quality improvement. Hence, research purpose is to explain the influence of accompanying facilitator on businees performance, and explaining the facilitator performance. Hence, Survey was conducted that employ PLS, the amount of population is 61 units, where as the sample si 19 unit. Research result shows that the funtion of facilitator has no significant on the UPK performance. Furthermore, it is known that $R^{2}$ that formulate facilitator function on business performance is $14.6 \%$. So, it is reccomended to improve accompanying model that needed to make impact on KSM performance.
\end{abstract}

\begin{abstract}
ABSTRAK
Program nasional pemberdayaan Masyarakat Mandiri Perkotaan (PNPM MP) mempunyai kekhususan dalam membantu Usaha Mikro melalui penyediaan modal dengan prinsip modal bergulir dan peningkatan kualitas sumber daya manusia. Dalam kaitan ini tujuan penelitian adalah menjelaskan pengaruh fasilitator pendamping terhadap tingkat kinerja keuangan, dan menjelaskan kinerja fasilitator. Untuk itu dilakukan survei yang menggunakan analisis PLS dengan jumlah populasi sebanyak 61 unit, dimana sampel sampel 19 unit. Hasil penelitian menunjukkan bahwaperan fasilitator pendamping tidak berpengaruh signifikan terhadap tingkat kinerja keuangan UPK.Lebih lanjut, diketahui bahwa $\mathrm{R}^{2}$ pembentuk fungsi fasilitator terhadap kinerja keuangan sebesar $14.6 \%$. Dengan demikian, disarankan perbaikan model pendampingan yang lebih sesuai dengan kebutuhan sehingga berdampak terhadap kinerja bisnis KSM.
\end{abstract}

Keyword: Village Facilitators,Job Description Facilitator, Financial Indicators, UPK, BKM

Korespondensi penulis e-mail: tonalubis@gmail.com 


\section{PENDAHULUAN}

\subsection{Latar belakang}

Usaha kecil dan menengah (UKM) mempunyai peran yang konkrit dan strategis dalam pertumbuhan ekonomi nasional dan penyerapan tenaga kerja. Menurut Kuncoro (2009), perhatian untuk menumbuh-kembangkan usaha kecil dan menengah (UKM) setidaknya dilandasi oleh tiga alasan. Pertama, UKM menyerap banyak tenaga kerja.Kedua, UKM memegang peranan penting dalam ekspor nonmigas.Ketiga, adanya urgensi untuk struktur ekonomi yang berbentuk piramida pada PJPT I menjadi semacam "gunungan" pada PJPT II. Selain hal itu, kecenderungan lokasi UMKM yang berada di daerah pedesaan akan menimbulkan dampak positif terhadap penyerapan tenaga kerja, jumlah kemiskinan yang menurun, pemerataan distribusi pendapatan, pembangunan ekonomi di pedesaan dan UMKM lebih banyak menggunakan sumberdaya alam local dalam berbagai kegiatan produksinya.

Grosh dan Somolekae (1996)dalam Lincolin Arsyad (2008)menawarkan tiga pendekatan untuk membimbing usaha-usaha seperti itu. Pertama,pendekatan kebijakan di tingkat perusahaan dapat membentuk faktor-faktor penunjang seperti peningkatan akses modal,pengadaan pelatihan bisnis untuk wirausahawaan dan perbaikan fasilitas-fasilitas seperti pengadaan kawasan industri yang difungsikan sebagai inkubator. Kedua, kebijakan makro ekonomi dapat membentuk faktor-faktor penunjang seperti reformasi keuangan dan perbaikan kebijakan-kebijakan struktur tarif dan nilai tukar mata uang asing. Ketiga, pendekatan melalui kerangka hukum/institusional/birokrasi supaya tersedia lingkungan yang mendukung bagi usaha mikro,seperti perubahan pada sistem kepemilikan tanah,perbaikan pada sistem perijinan dan pengaturan pada lembaga-lembaga keuangan termasuk pembuatan penjaminan simpanan,peraturan kehati-hatian dan pemeriksaan bank.

Lembaga keuangan mikro saling membutuhkan dengan usaha mikro.Lembaga ini sebagai agen jasa keuangan pada usaha mikro.Lembaga keuangan formal tidak mampu menjangkau usaha mikro secara efektif bila dibandingkan dengan pertumbuhan usaha mikro itu sendiri. Keunggulan dari Lembaga keuangan mikro antara lain pelayanan yang diberikan cepat dan mudah serta keberadaan lembaga keuangan mikro lebih dekat ke masyarakat sehingga lebih mengenal dari karakter peminjam atau nasabah.

Ghate (1992b) dalam Arsyad, L. (2008) menemukan setidaknya dua keunggulan komparatif LKM dalam melayani masyarakat berpenghasilan rendah yaitu kelenturan proses kredit mereka serta penyediaan pinjaman kecil dan jangak pendek. Kelenturan LKM dalam persoalan agunan membuat LKM tersebut dapat membiayai sejumlah besar kegiatan jasa tanpa harus ada agunan. Ghate menunjukan bahwa ketika si peminjam tidak dapat memberikan agunan,LKM tersebut akan memberikan pinjaman hanya berdasarkan informasi yang di peroleh secara langsung tentang si peminjam atau berdasarkan keterikatan dengan komunitasnya (Ghate,1992a).

\subsection{Perumusan Masalah}

Program nasional pemberdayaan Masyarakat Mandiri Perkotaan (PNPM MP) sebagai sebuah program yang digerakkan oleh masyarakat memberikan solusi pemecahan keterbatasan modal,keterbatasan sumber daya manusia yang dirasakan oleh usaha mikro dan masyarakat berpenghasilan rendah tersebut dengan melalui kegiatan ekonomi berupa pinjaman bergulir yaitu pemberian pinjaman dalam skala mikro kepada masyarakat miskin atauberpenghasilan rendah dengan melalui pendekatan kelompok yang disebut dengan 
Kelompok swadaya masyarakat (KSM). Setiap masyarakat yang ingin mendapatkan tambahan dana untuk usaha harus membentuk kelompok yang mana masing-masing saling mengenal. Sistem yang diterapkan dalam kegiatan pinjaman bergulir ini yaitu bersifat tanggung renteng. Sasaran utama kegiatan pinjaman bergulir adalah memberikan akses pinjaman pada rumah tangga miskin (pendapatan rendah) melalui kegiatan pinjaman bergulir untuk memperbaiki kondisi ekonominya dan memberikan pelajaran kepada peminjam mengenai penggunaan dana tersebut. Masyarakat diajarkan juga tata kelola keuangan yang baik seperti pembukuan melalui fasilitator kelurahan yang mendampingi mereka.

Fasilitator kelurahan adalah orang yang bertanggung jawab untuk memfasilitasi proses pemberdayaan di masyarakat. Fungsi utama fasilitator adalah mendampingi masyarakat dalam merumuskan dan memecahkan masalah kemiskinan melalui tahapan siklus, pelatihan, sosialisasi dan memenuhi kewajiban adminsitrasi proyek berupa laporan. Melalui pendampingan intensif dari fasilitator kelurahan, dapat diketahui kinerja keuangan

PNPM Mandiri perkotaan dalam perjalanannya melalui kegiatan pinjaman bergulirnya yaitu berupa bantuan modal dirasakan belum memadai terutama bagi masyarakat yang ingin membuka usaha baru. Selama ini Unit Pengelola Keuangan (UPK) lebih menitik-beratkan pada pelayanannya bagi masyarakat yang telah memiliki usaha dalam pengembangan usahanya.

Masalah tersebut di atas terjadi karena para pengurus belum bisa membuat suatu program kerja yang luwes dan sangat mementingkan pengembalian pinjaman sehingga bantuan modal hanya bisa dinikmati sebagian kecil masyarakat yang sudah mempunyai usaha terlebih dahulu. Ditambah lagi permasalahan tentang kualitas fasilitator pendamping di lapangan yang bertugas memberikan advice, dirasakan kurang maksimal peran dan fungsinya.

Dari fakta tersebut,maka ditemukan permasalahan yaitu bagaimana pengaruh Fasilitator pendamping terhadap tingkat kinerja keuangan Unit Pengelola Keuangan (UPK) dalam mengelola dana pinjaman bergulir pada PNPM Mandiri Perkotaan Kota Jambi

\subsection{Tujuan dan Manfaat Penelitian}

Tujuan penelitian ini adalah :

1. Untuk menganalisis pengaruh Fasilitator pendamping terhadap tingkat kinerja keuangan Unit Pengelola Keuangan (UPK) dalam mengelola dana pinjaman bergulir pada PNPM Mandiri Perkotaan di Kota Jambi.

2. Untuk menganalisis kinerja fasilitator di lapangan sebagai cerminan pendamping masyarakat yang mempunyai peranan untuk meningkatkan kapasitas UPK sebagai lembaga keuangan yang kuat secara organisasi dan sehat secara finansial.

\section{TINJAUAN PUSTAKA}

\subsection{Landasan Teoritis}

\subsubsection{Konsep dan definisi pemberdayaan}

Konsep pemberdayaan menurut Kabeer (1992); merujuk pada power as determining choice and ability to choose, yaitu kekuasaan untuk menentukan pilihan dan kemampuan untuk memilih. Lebih jelasnya, konsep ini berarti proses dengan mana mereka yang tidak berkemampuan untuk memilih menjadi berkemampuan untuk itu.

Definisi pemberdayaan yang sesuai dengan kerangka kerja kredit mikro menurut 
Mayoux (1998) adalah suatu istilah yang umum digunakan untuk mendeskripsikan proses dimana orang yang tidak berdaya menjadi sadar akan situasi mereka sendiri kemudian mengorganisasikan diri mereka secara kolektif, ditujukan untuk memperoleh akses yang lebih terhadap pelayanan publik serta untuk pengembangan tingkat ekonomi mereka (Rajivan,2001).

\subsubsection{Kredit Mikro}

Definisi mikro kredit pertama kali dicetuskan pada pertemuan The World Summit On Micro Credit di Washington tanggal 2 - 4 Februari 1997 yang menyatakan bahwa Kredit mikro yaitu "Programmes extend small loans to very poor for self employment project that generate income,allowing them to care for themselves and their families" atau program pemberian kredit dalam jumlah kecil kepada warga miskin untuk membiayai kegiatan produktif yang dia kerjakan sendiri agar menghasilkan pendapatan,yang memungkinkan mereka peduli terhadap dirinya sendiri dan keluarganya.

MenurutADB (2000) "Microfinance is the provision of a broad range of financialservices such as deposits, loans, payment services, money transfers, and insurance to poor and low-income households and, their microenterprises". Keuangan mikro adalah pelayanan keuangan yang dalam batasan ketentuannya seperti deposito,pinjaman,jasa pembayaran,transfer uang dan asuransi untuk pengusaha kecil dan rumah tangga berpenghasilan rendah dan miskin.

Kredit mikro ini umumnya disalurkan melalui Lembaga Keuangan Mikro baik formal maupun Informal. Lembaga kredit mikro di Indonesia pada dasarnya ada dua kelompok yakniBPR dan Koperasi,baik koperasi jasa simpan pinjam jasa keuangan maupun unit usaha simpan pinjam dalam berbagai macam koperasi. Masih ada LKM lain yang diperkenalkan oleh berbagai lembaga baik pemerintah seperti Lembaga Kredit Desa,Badan kredit kecamatan dan lain-lain,maupun swasta/lembaga non pemerintah seperti Bank BRI, Yayasan,LSM serta Lembaga keagamaan termasuk juga lembaga keuangan illegal.

\subsubsection{Lembaga Keuangan Mikro}

Menurut Undang-undang No.1 Tahun 2013 menyatakan bahwa Lembaga Keuangan mikro adalah lembaga yang khusus didirikan untuk memberikan jasa pengembangan usaha dan pemberdayaan masyarakat,baik melalui pinjaman atau pembiayaan dalam skala usaha mikro kepada anggota dan masyarakat,pengelolaan simpanan maupun pemberian jasa konsultasi pengembangan usaha yang semata-mata tidak mencari keuntungan.

Dalam bukunya Microfinance Handbook yang diterbitkan oleh Bank Dunia,Ledgerwood (1999) menyatakan istilah Lembaga Keuangan Mikro menunjuk pada penyediaan jasa-jasa keuangan (biasanya berupa simpanan dan kredit) kepada nasabah yang mempunyai penghasilan rendah yang meliputi pedagang kecil dan kaki lima,petani kecil,penjual jasa misal salon serta penarik becak serta tukang dan produsen yang memproduksi barang secara kecil misal pandai besi dan penjahit.

\subsubsection{Kinerja Keuangan}

Kinerja keuangan UPK dalam PNPM MP dapat dilihat dari beberapa rasio keuangan seperti tampak di Tabel 1.2.,yaitu Pertama,LAR (Loans at risk), kedua,PAR (Portfolio at risk), ketiga,ROI (Return on investment), keempat,CCR (Cost of coverage). Dari rasio-rasio tersebut akan didapat apakah kinerja keuangan UPK dalam kondisi sehat dan berjalan sehingga bisa tetap Sustain (berkelanjutan).

Tabel.2.1.Indikator kinerja pinjaman bergulir 


\begin{tabular}{|c|c|c|c|c|c|}
\hline No. & Indikator & Rumus & Satisfactory & Minimun & Suspend \\
\hline 1 & LAR & $\frac{\text { Jumlah KSM menunggak } \geq 3 \text { bulan }}{\text { Jumlah KSM Peminjam }}$ & $\leq 10 \%$ & $\leq 20 \%$ & $\geq 20 \%$ \\
\hline 2 & PAR & $\frac{\text { Pinjaman tertunggak } \geq 3 \text { bulan }}{\text { Realisasi saldo pinjaman }}$ & $\leq 10 \%$ & $\leq 20 \%$ & $\geq 20 \%$ \\
\hline 3 & ROI & $\begin{array}{c}\text { Laba bersih } \\
\text { Modal investasi }\end{array}$ & $\leq 10 \%$ & $\geq 0 \%$ & $\leq 0 \%$ \\
\hline 4 & CCR & $\begin{array}{c}\text { Total Pendapatan tunai UPK } \\
\text { Total biaya tunai UPK }\end{array}$ & $\geq 125 \%$ & $\geq 100 \%$ & $\begin{array}{c}\leq 100 \\
\%\end{array}$ \\
\hline
\end{tabular}

Sumber : Pedoman Teknis Pinjaman Bergulir PNPM MP

\subsubsection{Kerangka Pemikiran}

PNPM Mandiri Perkotaan dijadikan momen untuk tahap konsolidasi kegiatan keuangan mikro. Oleh sebab itu,dalam tahap ini perlu diciptakan UPK yang kuat secara kelembagaan,sehat dari segi finansial dan secara operasional terpisah dari BKM. Untuk mencapai kondisi UPK yang ideal tersebut,diperlukan tenaga pendamping (Fasilitator) yang terdidik dan berpengalaman serta paham terhadap keuangan mikro dengan pola pemberdayaan. Peranan Tenaga pendamping (Fasilitator) sangat vital bagi keberlanjutan UPK khususnya kegiatan pinjaman bergulir ke depan agar tetap survive karena salah satu faktor penyebab utamanya adalah keterbatasan sumber daya manusia di masyarakat yang rata-rata hanya berpendidikan rendah.

Dari uraian di atas,maka alur kerangka pemikiran yang digunakan dapat dilihat pada Gambar 2.1. berikut ini.

\section{Performa Fasilitator \\ 1. Kehadiran \\ 2. Koordinasi tatap muka \\ 3. Koordinasi by phone \\ 4. Penguasaan substansi/keteknisan program \\ 5. Motivasi \\ 6. Kepuasan BKM}

\section{Gambar 2.1. Alur kerangka pemikiran}

Berdasarkan rumusan masalah, beberapa penelitian sebelumnya serta kerangka teoritis yang dibuat, maka dapat diambil suatu hipotesis sebagai berikut

1. Tenaga pendamping (Fasilitator) mempunyai pengaruh yang sangat signifikan terhadap tingkat kinerja keuangan UPK sehingga bisa survive dan sustain kegiatan pinjaman bergulir

2. Tenaga pendamping (Fasilitator) mempunyai kinerja yang baik sebagai cerminan pendamping masyarakat yang mempunyai peranan dalam meningkatkan kapasitas UPK menjadi lembaga keuangan yang kuat secara organisasi dan sehat secara financial. 


\section{METODE PENELITIAN}

\subsection{Populasi dan Sampel}

Jenis ini adalah penelitian eksplanatoris(explanatory research). Populasi penelitian ini adalah Unit Pengelola Keuangan (UPK) yang diintervensi oleh PNPM MP.Sampel penelitian ditentukan dengan metode purposive sampling tipe judgement sampling. Dalam perumusan kriterianya,subjektivitas dan pengalaman peneliti sangat berperan karena peneliti mempunyai pertimbangan-pertimbangan tertentu di dalam pengambilan sampelnya.

Pertimbangan yang digunakan dalam mengambil sampel penelitian adalah:

1. Ketersedianya laporan keuangan yaitu Neraca dan Rugi Laba selama 3 tahun terakhir beserta data pendukung lainnya

2. Keterwakilan masing-masing tahun di intervensi oleh PNPM MPk

3. Kepengurusan organisasi yaitu BKM dan UPK masih aktif

4. Sering terjadinya turn over fasilitator pendamping di lapangan

Jumlah sampel yang akan diambil total sebanyak 19 Kelurahan di Kota Jambi yang diintervensi oleh PNPM MP. Secara lebih lengkap rincian sebaran jumlah Kelurahan dan sampel dapat dilihat dalam Tabel 3.2.berikut.

Tabel 3.2. Sebaran Rincian Sampel

\begin{tabular}{|c|c|c|c|c|c|}
\hline \multirow{2}{*}{ Wilayah } & \multirow{2}{*}{$\begin{array}{c}\text { Tahun } \\
\text { diintervensi } \\
\text { (PNPM MP) }\end{array}$} & \multicolumn{3}{|c|}{ Jumlah Kelurahan } & \multirow{2}{*}{$\begin{array}{c}\text { Jumlah } \\
\text { sampel }\end{array}$} \\
\cline { 3 - 6 } & Tahun 2011 & Tahun 2012 & Tahun 2013 & \\
\hline Kota Jambi & 2009 & 19 & 19 & 19 & 5 \\
\hline & 2008 & 14 & 14 & 14 & 5 \\
\hline & 2007 & 18 & 18 & 18 & 7 \\
\hline & 2006 & 10 & 10 & 10 & 2 \\
\hline & Total & 61 & 61 & 61 & 19 \\
\hline
\end{tabular}

Sumber : Data yang diolah

\subsection{Jenis data dan sumber data}

Berdasarkan sumber,penelitian menggunakan data primer dan data skunder.Data primer yaitu peneliti mengumpulkannya secara langsung. Data skunder yaitu data yang diperoleh atau dikumpulkan oleh peneliti dari berbagai sumber yang telah ada (peneliti sebagai tangan kedua). Data sekunder diperoleh dari :

(1) Data dariweb.p2kp.org/mk berupa laporan keuangan dari Tahun 2011 s/d 2013 serta informasi keuangan lainnya.

(2) Data dari Bank Indonesia perwakilan Provinsi Jambi (2013). Laporan Tahunan Triwulan ke-III untuk Tahun 2013 dan Laporan Tahunan 2011 serta 2012.

(3) Data dari Badan Pusat Statistik (BPS) tentang pertumbuhan ekonomi dan penyerapan tenaga kerja (2008). 


\subsection{Operasionalisasi Variabel}

Variabel penelitian terdiri atas dua variabel yaitu Tugas dan tanggung jawab (Fasilitator kelurahan) adalah sebagai Variable Independen (X) yang terdiri dari tujuh indikator yaitu tingkat kehadiran(X.1),Intensitas Komunikasi secara langsung(X.2),intensitas komunikasi melalui telpon (X.3),Motivasi (X,4),penguasaan substansi/keteknisan (X.5),Kepuasan Masyarakat (X.6) dan Variabel Manajemen Keuangan sebagai Variabel Dependen (Y) yang terdiri dari Empat indikator yaitu LAR(Y.1),PAR (Y.2),CCR (Y.3),ROI (Y.4).

\subsection{Metode pengumpulan data}

Teknikpengumpulan data yang digunakan yaitu wawancara dan observasi. Wawancara semi terstruktur dilakukan kepada pengurus Badan Keswadayaan masyarakat atau Unit Pengelola keuangan.Observasi adalah dengan melakukan pengamatan terhadap objek yang diwawancarai guna mencari dan meyakinkan kebenaran informasi yang diberikan.

\subsection{Skala Likert}

Skala pengukuran yang digunakan adalah modifikasi skala Likert yaitu dari 1 sampai 5 . Adapun penggunaan skala $1-5$ untuk setiap jawaban responden selanjutnya dibagi dalam lima kategori yaitu : Sangat Baik (SB), Baik (B), Sedang (S), Kurang (K) dan Kurang Sekali $(\mathrm{KS})$.

\subsection{Pembobotan Nilai}

Sebelum diolah, diberikan pembobotan terlebih dahulu atas Jawaban responden yang di kuisioner. Skala jawaban kuisioner dengan menggunakan skala Likert (J.Supranto,2003) terdapat pada Tabel 3.3. di bawah ini:

Tabel.3.3. Pembobotan nilai

\begin{tabular}{|c|c|}
\hline Skor & Penilaian \\
\hline 1 & Kurang Sekali \\
\hline 2 & Kurang \\
\hline 3 & Sedang \\
\hline 4 & Baik \\
\hline 5 & Sangat Baik \\
\hline
\end{tabular}

Sumber : Data diolah

Untuk mengetahui range,maka selisih antara bobot nilai tertinggi dengan bobot nilai terendah adalah $5-1=4$, dan untuk mengetahui jumlah interval dan besar interval dapat digunakan dengan rumus sebagai berikut:

K 5

$$
\mathrm{t}=\underline{\mathrm{R}}=\underline{4}=0.8
$$

Keterangan :

$$
\begin{aligned}
& \mathrm{R}=\text { range (kelas) } \\
& \mathrm{K}=\text { Jumlah Interval Kelas } \\
& \mathrm{I}=\text { Besar Interval Kelas }
\end{aligned}
$$


Berdasarkan ketentuan di atas,maka tanggapan responden berdasarkan batas-batas penelitian terhadap bagian-bagian yang dievaluasi dapat dikelompokkan sebagai berikut:

Tabel3.4. Interval Penilaian

\begin{tabular}{|c|c|}
\hline Batasan & Keterangan \\
\hline $1-1.8$ & Kurang Sekali \\
$1.81-2.6$ & Kurang \\
$2.61-3.4$ & Sedang \\
$3.41-4.2$ & Baik \\
$4.21-5$ & Sangat Baik \\
\hline
\end{tabular}

Sumber : Data diolah

\subsection{Analisis data}

Analisis data penelitian terbagi menjadi 2 jenis, yaitu statistik deskriptif dan statistik inferensial.

\section{- Statistik Deskriptif}

Analisis statistik deskriptif digunakan untuk memberikan gambaran atau deskriptif empiris atas data yang dikumpulkan dalam penelitian (Ferdinand, 2006). Penelitian ini menggunakan analisis statistik deskriptif berupa statistik rata-rata.

\section{- Statistik Inferensial}

Statistik inferensial dalam penelitian ini menggunakan analisis kausalitas SEM (StructuralEquation Modeling) berbasis component atau variance yang terkenal dengan Partial Least Square (PLS). Penelitian ini menggunakan software SmartPLS versi 1.10 .

\section{HASIL DAN PEMBAHASAN}

\subsection{Profil Responden}

Analisis data profil responden diambil sebanyak 19 orang pengurus yang mewakili 19 BKM di Kota Jambi.Hasil analisis data responden,didapat 5 karakteristik responden yang terangkum dalam Tabel 4.1. di bawah ini. 
Tabel 4.1 Profil pengurus BKM di Kota Jambi

\begin{tabular}{|c|c|c|c|}
\hline No & Atribut pengurus & Keterangan & Persentase \\
\hline \multirow[t]{2}{*}{1} & \multirow[t]{2}{*}{ Jenis kelamin } & Laki-laki & $78.94 \%$ \\
\hline & & Perempuan & $21.50 \%$ \\
\hline \multirow{4}{*}{2} & \multirow{4}{*}{ Umur } & $30-40$ & $10.52 \%$ \\
\hline & & $41-50$ & $36.84 \%$ \\
\hline & & $51-60$ & $42.10 \%$ \\
\hline & & $>60$ & $10.52 \%$ \\
\hline \multirow[t]{4}{*}{3} & \multirow{4}{*}{ Pendidikan } & SD & $0 \%$ \\
\hline & & SMP & $15.78 \%$ \\
\hline & & SMA & $63.15 \%$ \\
\hline & & Sarjana & $21.50 \%$ \\
\hline \multirow{4}{*}{4} & \multirow{4}{*}{ Jabatan } & $\mathrm{BKM}$ & $100 \%$ \\
\hline & & Sekretaris & $0 \%$ \\
\hline & & UPK & $0 \%$ \\
\hline & & Lain-lain & $0 \%$ \\
\hline \multirow{4}{*}{5} & \multirow{4}{*}{ Lama kepengurusan } & $<1$ thn & $5.26 \%$ \\
\hline & & $1-3$ thn & $0 \%$ \\
\hline & & $3-5$ thn & $73.68 \%$ \\
\hline & & $>5$ thn & $21.50 \%$ \\
\hline
\end{tabular}

Sumber : Data diolah dari responden

Setelah analisis data dilakukan analisis kuantitatif. Teknis yang digunakan adalah model Partial Least Square (PLS) dengan Software SmartPLS versi 1.10.

\subsection{Menentukan Signifikansi Pengaruh Antara Variabel Terhadap Indikator}

\subsubsection{Perhitungan Model}

Hasil perhitungan model penelitian dengan SmartPLS tersebut seperti terlihat di bawah ini:

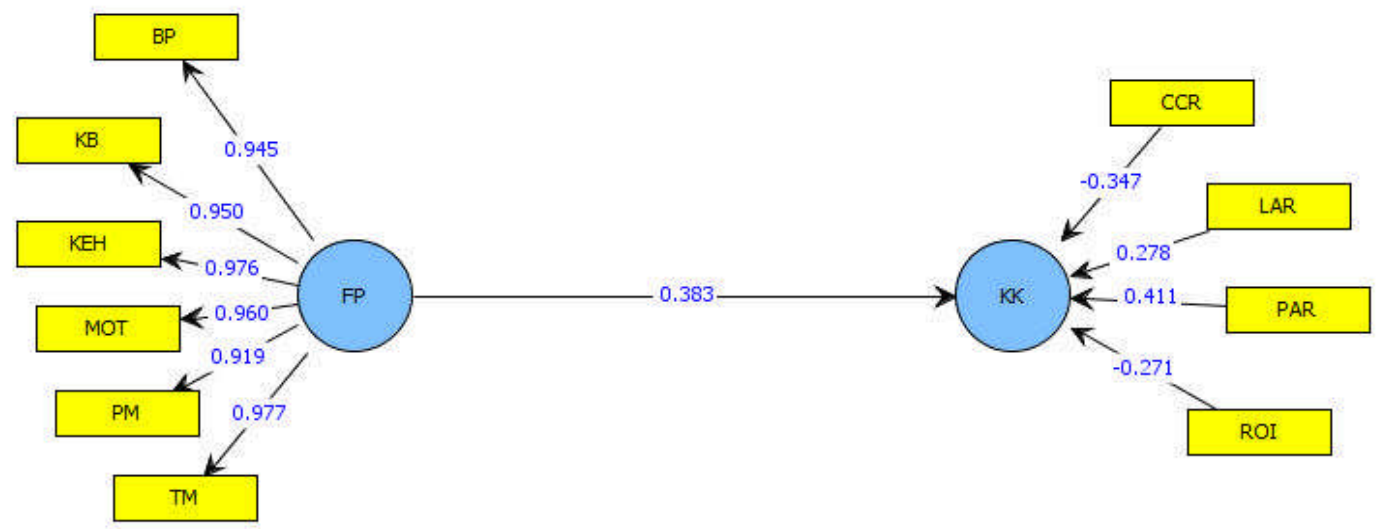

Gambar 1. Hasil Perhitungan Model Penelitian 
Menurut Chin (1998) dalam Ghozali (2006) suatu indikator dianggap mempunyai reliable jika memiliki nilai korelasi diatas 0.70 . Namun pada riset pengembangan skala,loading factor 0.50 sampai 0.60 masih dapat diterima. Berdasarkan perhitungan dengan mengggunakan SmartPLS pada Gambar 1. terlihat bahwa semua indikator untuk variabel fasilitator pendamping memiliki loading factor diatas 0.50 sehingga merefleksikan peran fungsi sebagai fasilitator pendamping di masyarakat.

Hasil kalkulasi terhadap variabel fasilitator pendamping pada Gambar 2. menunjukkan bahwa indikator komunikasi melalui tatap muka (TM) memiliki loading factor tertinggi yaitu 0.977, sedangkan pada variabel indikator fasilitator pendamping melalui penguasaan materi (PM) memiliki loading factor terendah yaitu 0.919. Hasil kalkulasi terhadap variabel kinerja keuangan juga menunjukkan indikator PAR mempunyai loading factor tertinggi yaitu 0.414,sedangkan indikator ROI mempunyai loading factor terendah yaitu -0.271 .

\subsubsection{Bootstrapping Terhadap Model}

Setelah kalkulasi selanjutnya dilakukan bootstrapping terhadap model baru dengan hasil dapat dilihat pada Gambar 4.2. berikut.

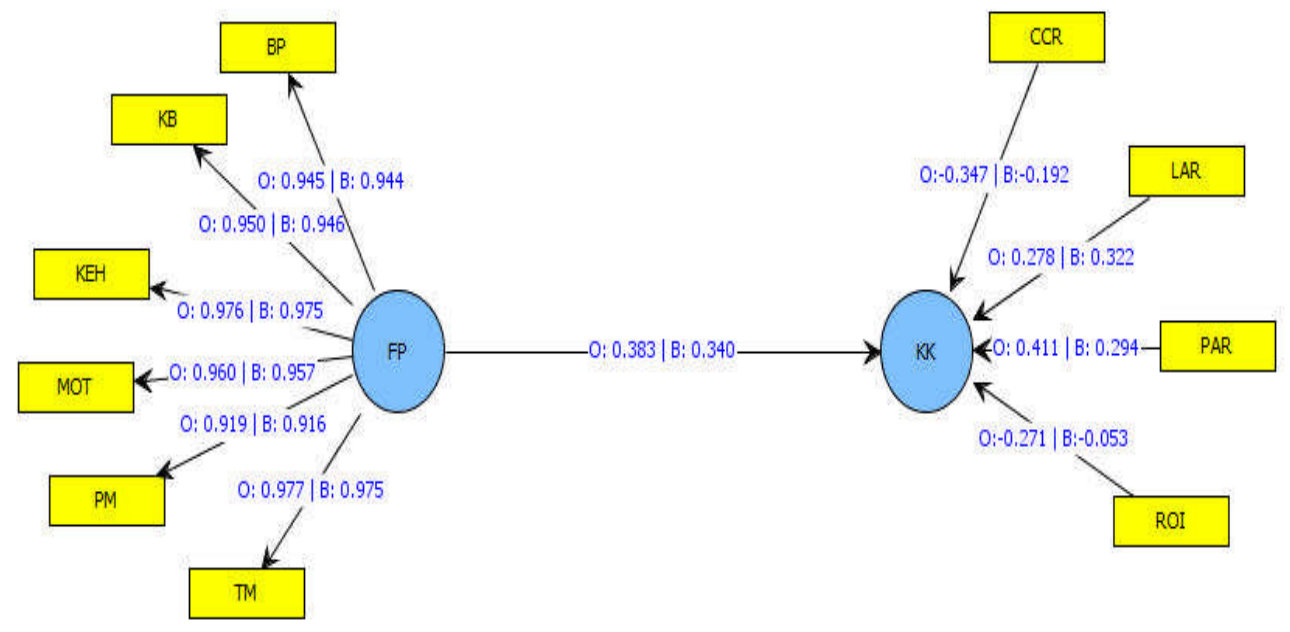

Gambar 2. Hasil Bootstrapping Terhadap Model Baru

\subsubsection{Menilai Outer Model Atau Measurement Model}

Kegunaan menilai outer model adalah untuk melihat korelasi antara indikator suatu konstruk dengan korelasi indikator tersebut dengan konstruk lainnya.Hasil penilaian outer model seperti terlihat pada Tabel 4.2..di bawah ini. 
Tabel 2. Result for outer loading

results for outer loadings

[ CSV-Version ]

\begin{tabular}{|c|c|c|c|c|}
\hline & $\begin{array}{c}\text { original sample } \\
\text { estimate }\end{array}$ & $\begin{array}{c}\text { mean of } \\
\text { subsamples }\end{array}$ & $\begin{array}{c}\text { Standard } \\
\text { deviation }\end{array}$ & T-Statistic \\
\hline FP & & & 0.013 & 74.434 \\
\hline BP & 0.945 & 0.944 & 0.018 & 51.659 \\
\hline KB & 0.950 & 0.946 & 0.010 & 101.112 \\
\hline KEH & 0.976 & 0.975 & 0.011 & 87.154 \\
\hline MOT & 0.960 & 0.957 & 0.025 & 36.646 \\
\hline PM & 0.919 & 0.916 & 0.007 & 145.833 \\
\hline TM & 0.977 & 0.975 & & 1.542 \\
\hline KK & & & 0.493 & 2.018 \\
\hline CCR & -0.760 & -0.522 & 0.438 & 2.029 \\
\hline LAR & 0.885 & 0.676 & 0.435 & 1.241 \\
\hline PAR & 0.882 & 0.671 & 0.378 & \\
\hline ROI & -0.470 & -0.264 & & \\
\hline
\end{tabular}

Tabel 2. menggambarkan bahwa konstruk fasilitator pendamping memiliki discriminant validity yang tinggi karna semua indikator memiliki loading factor di atas 0.70 serta tingkat signifikan t-statistik di atas 1.96 (tingkat signifikan dilihat dari variabel yang memilki tstatistik di atas 1.96). Sedangkan konstruk kinerja keuangan yang memiliki discriminant validity tinggi yaitu indikator LAR dengan loading factor 0.885 (> 0.5) serta tingkat signifikan t-statistik $2.016(>1.96)$ dan indikator PAR dengan laoding factor $0.882(>0.5)$ serta tingkat signifikan t-statistik 2.029.(1.96). Untuk indikator CCR memiliki laoding factor $0.760(<0.50)$ dengan tingkat signifikan t-statistik $1.542(<1.96)$ dan ROI memiliki loading factor $-0.470(<0.50)$ dengan tingkat signifikan $1.241(<1.96)$. berdasarkan Tabel 5.2 indikator kinerja keuangan terlihat bahwa indikator yang memiliki nilai t-statistik dibawah 1.96 adalah indikator CCR dan ROI. Hal ini berarti indikator tersebut tidak signifikan.Dengan demikian dapat disimpulkan bahwa indikator tersebut bukan sebagai pembentuk variabel kinerja keuangan.

\subsubsection{Inner Model}

Untuk mengevaluasi model struktural digunakan $R$-square untuk konstruk dependen serta uji t untuk melihat signifikansi dari koefisien jalur struktural. Jika terjadi perubahan nilai $R$-square dapat digunakan untuk menilai pengaruh variabel laten independen tertentu terhadap variabel laten dependen apakah mempunyai pengaruh yang substantive. Hasil koefisien jalur struktural dan indikator beserta nilai signfikansinya seperti terlihat pada output di bawah ini.

Tabel 5.6. Hasil R-square

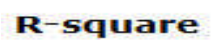

[ CSV-Version ]

\begin{tabular}{|c|c|}
\hline & R-square \\
\hline FP & \\
\hline KK & 0.146 \\
\hline
\end{tabular}


Terlihat bahwa pembentuk variabel fasiltator pendamping terhadap variabel kinerja keuangan sebesar 14.6\%. Hal ini menyimpulkan bahwa selisih $85.4 \%$ menunjukkan bahwa ada variabel lain yang mempengaruhi tingkat kinerja keuangan UPK. Pola pendampingan langsung kepada kelompok swadaya masyarakat (KSM) yaitu sebagai penerima manfaat akan sangat berpengaruh terhadap tingkat kinerja keuangan UPK sehingga bisa tetap sustain dan survive. Data hasil survey terhadap responden mengenai lama menjabat sebagai BKM menunjukan bahwa sebanyak 95,18\% responden sudah mengabdi di atas 3 tahun,sehingga penilaian kinerja fasilitator pendamping ini diasumsikan sama untuk tahun-tahun sebelumnya

Tabel 4.7. Result for inner weights

\section{results for inner weights}

[ CSV-Version ]

\begin{tabular}{|c|c|c|c|c|}
\hline & $\begin{array}{c}\text { original sample } \\
\text { estimate }\end{array}$ & $\begin{array}{c}\text { mean of } \\
\text { subsamples }\end{array}$ & $\begin{array}{c}\text { Standard } \\
\text { deviation }\end{array}$ & T-Statistic \\
\hline FP $\rightarrow$ KK & 0.383 & 0.340 & 0.281 & 1.363 \\
\hline
\end{tabular}

Hasil estimasi di atas menunjukkan bahwa koefisien parameter hubungan antara fasilitator pendamping ke kinerja keuangan adalah 0.383 dan t-statitsik 1.363, sehingga dapat disimpulkan bahwa fasilitator pendamping tidak berpengaruh signifikan terhadap tingkat kinerja keuangan. Hal ini dikarenakan konstruk fasilitator pendamping terhadap tingkat konstruk kinerja keuangan mempunyai loading factor dibawah 0.5 dengan tingkat signifikan tstatistik dibawah 1.96 (tingkat signifikansi dilihat dari variabel yang memiliki t-statistik diatas 1.96).

Berdasarkan hasil tabel di atas, fasilitator pendamping telah melaksanakan tugasnya dengan baik di lapangan sesuai dengan deskripsi pekerjaan yang telah diberikan. Indikator kehadiran,koordinasi tatap muka,koordinasi melalui telepon,penguasaan materi,motivasi serta kepuasan BKM telah merefleksikan peran fasiltator sebagai pendamping masyarakat.

Pola pendampingan langsung kepada kelompok swadaya masyarakat (KSM) yaitu sebagai penerima manfaat akan sangat berpengaruh terhadap tingkat kinerja keuangan UPK sehingga bisa tetap sustain dan survive.

\section{KESIMPULAN DAN SARAN}

\subsection{Kesimpulan}

1. Fasilitator pendamping tidak berpengaruh secara signifikan terhadap tingkat kinerja keuangan UPK sebagai pengelola kegiatan pinjaman bergulir di PNPM MP Kota Jambi

2. Fasilitator pendamping telah melaksanakan tugasnya dengan baik sesuai deskripsi pekerjaan yang diberikan. Indikator Kehadiran, Koordinasi tatap muka, Koordinasi melalui telepon,Penguasaan materi,Motivasi serta kepuasan BKM mempunyai signifikansi dalam merefleksikan variabel peran sebagai fasilitator pendamping dalam masyarakat karena mempunyai loading factor di atas 0.50 dengan tingkat signifikan tstatistik di atas 1.96 . 


\subsection{Saran}

1. Perlunya keterlibatan peran PEMDA sebagai stake holder sehingga bisa membuat kebijakan yang dapat mendukung pertumbuhan usaha mikro. Ketersediaan dana sharing serta persiapan dalam rangka alih kelola (take over) PNPM dari pemerintah pusat ke pemerintah daerah.

2. Diharapkan kepada peneliti berikutnya agar dapat meneliti lebih dalam lagi yaitu kepada kelompok peminjam atau penerima manfaat langsung dari kegiatan pinjaman bergulir di PNPM Mandiri Perkotaan.

\section{DAFTAR PUSTAKA}

ADB, (2000), Finance The Poor,Microfinance Development Strategy.Asian Development Bank

Arsyad,Lincolin. (2008). Lembaga Keuangan Mikro. Institusi,Kinerja dan Sustainabilitas, Penerbit Andi,Yogyakarta

Fadilah,Yusuf (2006). Evaluasi Program Bantuan Dana Bergulir (Artikel)

Firman,Salim,Hadiwidjojo dan Armanu. (2014). Sustainability of Rural Microfinance Institution in Buton District of Southeast Sulawesi Province, International Journal of Bussiness and Management Invention,Volume 3 Issue 1 January,2014/PP.67-81

Ghozali,Imam (2006). Structural Equation Modeling,Metode Alternatif Dengan Partial Least Square, Semarang,Badan PenerbitUniversitas Diponegoro.

(2013). Indonesia:Evaluasi Program Pembangunan Berbasis Masyarakat Perkotaan (ICDD), Kementrian Pekerjaan Umum

(2012). Petunjuk Teknis Pinjaman Bergulir, PNPM Mandiri Perkotaan.Kementrian Pekerjaan Umum

Kuncoro,Mudrajat (2006). Pemberdayaan UKM: Antara Mitos dan Realitas. PUS-TEP-UGM

Rizarta Viking.(2006). Penguatan Kelembagaan Usaha Ekonomi Desa Simpan Pinjam Dalam

Pengembangan Ekonomi Lokal Di Desa Koto Teluk Kecamatan Hamparan Rawang

Kabupaten Kerinci (Disertasi),Institut Pertanian Bogor.

Somantri dan Muhidin (2006),Statistika Dalam Penelitian,Pustaka Setia,Bandung.

Supranto,J. (2009). Statistik,Teori Dan Aplikasi, Edisi ke-tujuh. Erlangga. Jakarta.

Syafrida Enny,Ma'mun sarma dan Wilson halomoan Limbong. (2013). Dampak Pemberian

Kredit Terhadap Peningkatan Pendapatan Usaha Kecil Masyarakat Pesisir Oleh Koperasi Lembaga Ekonomi Pengembangan Pesisir Mikro Mitra Mina Di Kabupaten Tuban,Jurnal Ilmiah,vol 8, no 1,IPB,Bogor.

UU No 1 tahun 2013 tentang UMK, Lembaran Negara No.12. Kementrian Hukum dan Hak Asasi Manusia Republik Indonesia

Widayati,Sri (2013),Pemberdayaan Ekonomi Melalui Dana Bergulir PNPM Mandiri Perdesaan Bagi Kelompok Simpan Pinjam Perempuan Di Desa Sraten Kabupaten Semarang,Jurnal Ilmiah Inkoma, Volume 24,Nomor 1,Februari 2013. 